\title{
Da moda para os
}

\section{oceanos}

\section{Sandra Rodrigues Maia}

Mestra, Universidade do Estado de Minas Gerais/ sandra maia@ymail.com

Orcid: 0000-0003-0623-1136/ lattes

\section{Eduardo Romeiro}

Doutor, Universidade Federal de Minas Gerais/ romeiro@dep.ufmg.br Orcid: 0000-0002-5574-5312/ lattes

\section{Rosangela Mendonça}

Doutora, Universidade Federal de Minas Gerais/ romiriam@gmail.com

Orcid: 0000-0002-1169-8980/ lattes

Enviado: 19/03/2021 // Aceito: 15/07/2021 


\title{
Da moda para os oceanos
}

\begin{abstract}
RESUMO
A presença de microfibras plásticas no oceano é um problema complexo que demanda soluções urgentes. Recentes pesquisas demonstraram que uma das fontes dessas ínfimas partículas está associada aos tecidos sintéticos destinados à confecção de roupas. Recolhê-las dos ambientes aquáticos é uma tarefa praticamente impossível. As soluções, por hora, dependem de ações que minimizem as emissões destas partículas. Este estudo reúne 2 propostas para melhor compreendê-las e levantar seus prós e contras.
\end{abstract}

Palavras-chave: Moda. Sustentabilidade. Poluição Plástica. 


\title{
From Fashion for oceans
}

\begin{abstract}
The presence of plastic microfibers in the ocean is a complex problem that requires urgent solutions. Recent research has shown that one of the sources of these tiny particles is associated with synthetic fabrics intended for making clothes. Collecting them from aquatic environments is an almost impossible task. The solutions, per hour, depend on actions that minimize the emissions of these particles. This study brings together 2 proposals to better understand them and raise their pros and cons.
\end{abstract}

Keywords: Fashion. Sustainability. Plastic Pollution. 


\title{
De la moda para los océanos
}

\begin{abstract}
RESUMEN
La presencia de microfibras de plástico en el océano es un problema complejo que requiere soluciones urgentes. Investigaciones recientes han demostrado que una de las fuentes de estas pequeñas partículas está asociada con las telas sintéticas destinadas a la confección de ropa. Recogerlos de ambientes acuáticos es una tarea casi imposible. Las soluciones, por hora, dependen de acciones que minimicen las emisiones de estas partículas. Este estudio reúne 2 propuestas para comprenderlos mejor y plantear sus pros y contras.
\end{abstract}

Palabras clave: Moda. Sustentabilidad. Contaminación plástica. 


\section{INTRODUÇÃO}

Mar de plástico. Este foi o título da revista National Geographic de julho de 2018. Na capa, a icônica imagem de uma sacola plástica representando um iceberg, denuncia o tamanho do problema com o qual o leitor irá se deparar. Os resíduos plásticos no ambiente marinho são motivo de pesquisas desde a década de 70 (JAME MOORE, 2015), mas o real impacto destes resíduos, bem como, a quantidade que chega aos oceanos por meio do ambiente terrestre até pouco tempo eram questões desconhecidas. Em 2015 uma pesquisa liderada pela professora de Engenharia Ambiental na Universidade da Geórgia (USA), Jenna Jambeck, apresentou a estimativa de que, anualmente, cerca de 8 milhões de toneladas de plástico chegam aos oceanos. Segundo o estudo, esta quantidade só tende a crescer em função do aumento global da população e da maior demanda pelo material plástico, podendo chegar a 250 toneladas anuais em 2025. Mas isso é apenas a ponta do iceberg. Enquanto uma parte dos resíduos pode ser recolhida, como garrafas PET, sacolas e uma infinidade de embalagens plásticas, outra parcela do material permanece invisível aos nossos olhos. O plástico no meio ambiente não é biodegradável, mas é continuamente fragmentado, transformando-se em micropartículas. Pouco se sabe sobre os efeitos nocivos dessas partículas, mas, entre outros, considera-se que causam danos irreversíveis à fauna marinha e riscos à saúde de seres humanos que acabam ingerindo as partículas em sua alimentação (GALL; THOMPSON, 2015; ROKCHMAN et al, 2013). Por outro lado, há que se considerar os mercados que esse material movimenta, os empregos que gera e sua utilidade. Portanto a solução não está em apenas banir o uso dos plásticos. Neste sentido diversas iniciativas estão surgindo tanto no mercado 
quanto no meio científico buscando reduzir a poluição provocada por esse material, em seus difersos formatos e em sua escala macro e micro. Para este estudo selecionou-se duas propostas que procuram tratar a questão do microplástico, com o objetivo de refletir sobre seus prós e contras.

\section{TECIDOS, FIBRAS E SUSTENTABILIDADE}

O tecido, material utilizado na confecção do vestuário, está ligado a todo tipo de impacto sobre a sustentabilidade: alterações climáticas; poluição das águas; perda da biodiversidade; uso excessivo ou inadequado de recursos não renováveis; geração de resíduos; prejuízos sobre a saúde humana e efeitos nocivos para as comunidades produtoras. Todos os materiais afetam de alguma forma os sistemas ecológicos e sociais, mas esses impactos diferem de uma fibra para outra quanto ao tipo e à escala (FLETCHER; GROSE, 2011).

Para muitos designers de moda a escolha dos tecidos e das técnicas têxteis de fabricação é a primeira etapa para o desenvolvimento de uma coleção. De modo geral, um tecido é selecionado conforme seu peso, textura, caimento e manuseio, como também pelo seu apelo estético e preço (GWILT, 2014). Porém, hoje, o designer precisa basear-se também nas questões socioambientais ligadas a cada decisão de projeto, o que inclui um amplo conhecimento relativo ao material têxtil selecionado (CARVALHAL, 2016; FLETCHER; GROSE, 2011; GWILT, 2004).

As fibras têxteis são classificadas em; fibras naturais, que se subdividem de acordo com sua origem em vegetais, animais e minerais como algodão, lã e amianto respectivamente; e fibras manufaturadas que se subdividem 
em polímeros naturais e sintéticos. Os polímeros naturais podem ser de origem vegetal como as fibras de celulose (viscose e liocel) ou de origem animal que são fibras de proteína regenerada proveniente da caseína (leite), soja e concha de caranguejo (FLETCHER; GROSE, 2011; HENRY et al., 2018). As fibras plásticas estão incluídas na classe dos polímeros sintéticos (poliéster, nylon e poliamidas) e são formadas por meio de reações químicas controladas. O petróleo é a fonte de aproximadamente $2 / 3$ de todos os tecidos sintéticos produzidos atualmente (HENRY, 2018). Curiosamente o poliéster PET (Polietileno Tereftalato), mais conhecido pela produção de garrafas, foi criado em 1940 pela indústria têxtil para a confecção de fibras de roupas no final da segunda Guerra Mundial. A ideia era gerar alternativas viáveis para substituir as fibras naturais (algodão, linho, lã) cujos campos estavam destruídos pela guerra (MARÇON, 2012). Os tecidos de poliéster apresentam características físicas interessantes como; maior durabilidade, rápida secagem e pouco amarrotamento. Por outro lado, um tecido $100 \%$ poliéster não permite a transpiração o que causa um grande desconforto térmico. A partir da década de 70 o fio de PET passa a ser misturado ao de algodão conferindo algumas valiosas propriedades ao tecido; estabilidade dimensional, que impede que o tecido encolha ou entorte, solidez na cor, resistência e durabilidade (ABIPET. 2010; MARÇON, 2012).

Ainda que as fibras naturais de origem vegetal ou animal dominem o mercado, as fibras sintéticas estão sendo cada vez mais utilizadas. De acordo com o relatório The Fiber Year (2017) estima-se que 65 milhões de toneladas de polímeros plásticos foram produzidas para a confecção de tecidos em 2016.

O modelo de negócio que se iniciou na década de 90 e domina atualmente o mercado da moda é um ponto chave 
para o aumento do uso de tecidos sintéticos como o poliéster (THE FIBER YEAR, 2017). O fast fashion, nome dado a este modelo de negócio, tem como objetivo vender mais em um intervalo de tempo cada vez menor. Para alcançar este objetivo oferece produtos com apelo de moda a preços mais baixos e em constante renovação (omitido para revisão cega). Conhecido por "democratizar" a moda, este sistema de produção estimula o consumismo através da obsolescência programada seja pela pouca durabilidade das peças ou pela rápida substituição de tendências. Em 30 anos o consumo de moda aumentou $400 \%$ e os consumidores precisam de muito menos dinheiro para comprar muito mais roupas (CARVALHAL, 2016; FLETCHER; GROSE, 2011; MCKINSEY, 2016). O aumento do consumo do poliéster acompanha a expansão do fast fashion como demonstrado no Gráfico 1. "A demanda de poliéster ultrapassou a de algodão em 2002 e continuou a crescer a uma taxa significativamente mais rápida do que todas as outras fibras tipos" (CARMICHAEL, 2015).

Gráfico 1. Demanda de fibras têxteis 1980-2030

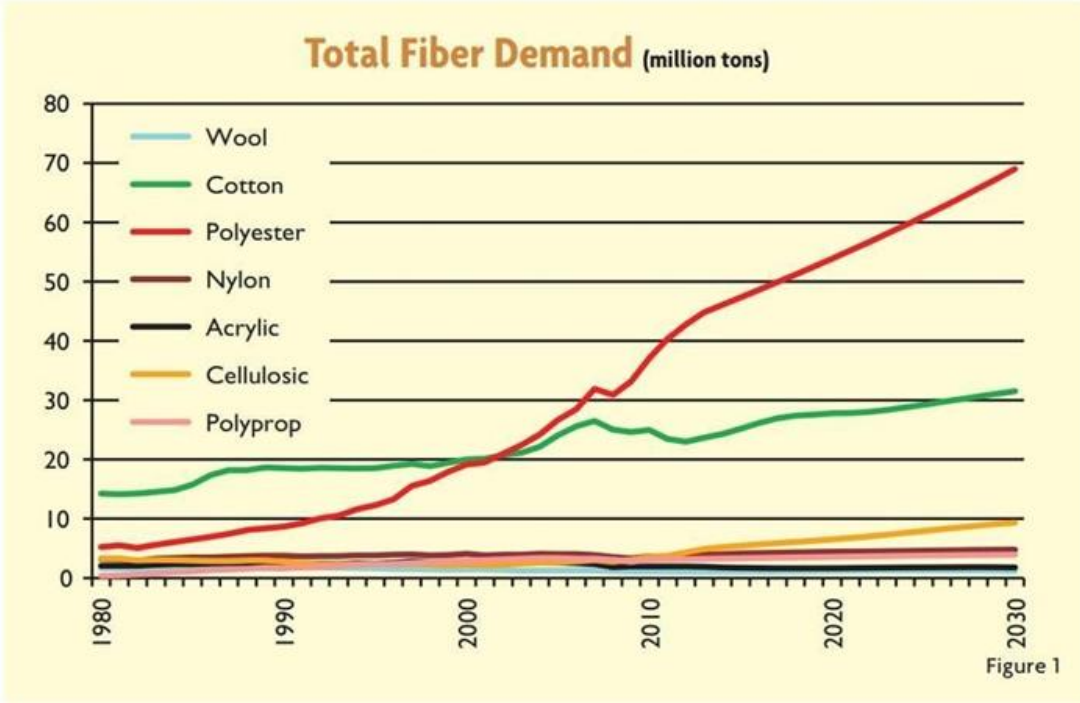

Fonte: CARMICHAEL (2015). 


\subsection{Principais fontes de microbribras plásticas no oceano e a cadeia têxtil}

Embora promover o crescimento do negócio seja o objetivo de tal velocidade, a consequência inevitável é o aumento dos impactos negativos sobre o meio ambiente, o que ocorre ao longo de toda a cadeia produtiva do vestuário (FLETCHER; GROSE, 2011) - por exemplo, tecidos liberam fibras durante sua produção, uso e quando são descartados, (HENRY et al., 2018) causando, em função de sua matéria prima e quantidade, diferentes impactos ao meio ambiente.

Materiais como nylon, acrílico e PET (Polietileno Tereftalato ou poliéster) estão presentes na fabricação de diversos tecidos conferindo-Ihes importantes características como durabilidade e praticidade.

As malhas produzidas com o poliéster reciclado das garrafas PET's possuem uma mistura de $50 \%$ algodão e $50 \%$ poliéster. Estudos comprovam que essa mistura gera resultados de vida longa aos artigos, o que leva alguns clientes a buscarem artigos nessa composição, e a existência de artigos com dessa composição feitas com garrafas PET's recicladas acabam unindo o útil ao agradável. Quanto à maciez e conforto das malhas $100 \%$ algodão, não há o que discutir, a fibra é uma das utilizadas no mundo, e se cultivada de forma sustentável, sem usos de agrotóxicos, se torna ainda melhor. (LOPO, 2017, p. 12).

Por outro lado, é a partir destes materiais que microfibras plásticas são liberadas. Uma das origens destas micropartículas se dá em função da ação de fatores naturais como fotodegradação (degradação pela ação da luz), hidrólises (degradação pela ação da água) e termo degradação (degradação pela temperatura) (ANDRADY, 2011). Outra fonte, compreendida como fonte primária, está diretamente ligada à indústria da moda, mais precisamente 
aos tecidos sintéticos. Os estudos dos cientistas, Napper e Thompson (2016), da Universidade de Plymouth (Inglaterra) revelaram grandes perdas de microfibras pelas máquinas domésticas de lavar roupas. De acordo com a pesquisa a cada ciclo de lavagem com uma carga de 6 quilos, centenas de milhares de microfibras são liberadas. Em uma escala global, estima-se que 35\% de todo microplástico primário que chega aos oceanos seja proveniente da lavagem de tecidos sintéticos (BOUCHER; FRIOT, 2017). Micropartículas de plástico menores que $5 \mathrm{~mm}$ - esferas, fragmentos e filamentos (ARTHUR et al., 2009) - se espalham pelo oceano de tal forma que, hoje é possível afirmar que se encontram em praticamente todas as regiões marinhas; dos polos ao equador (THOMPSON et al.,2004, 2005; JAMBECK, 2015; HENRY, 2018; BARNES et al., 2009; BROWNE et al., 2011; WAGNER et al., 2014).

Como nem as máquinas de lavar, nem as estações de tratamento da água conseguem filtrar essas micropartículas, elas chegam aos rios, lagos e oceanos. (HENRY et al., 2018; NAPPER; THOMPSON, 2016). Assim, os têxteis sintéticos são apontados como principal fonte de microfibras plásticas nos ambientes aquáticos (NAPPER; THOMPSON, 2016) como demonstrado no gráfico 2.

Gráfico 2: De onde vêm os micro plásticos dos oceanos?

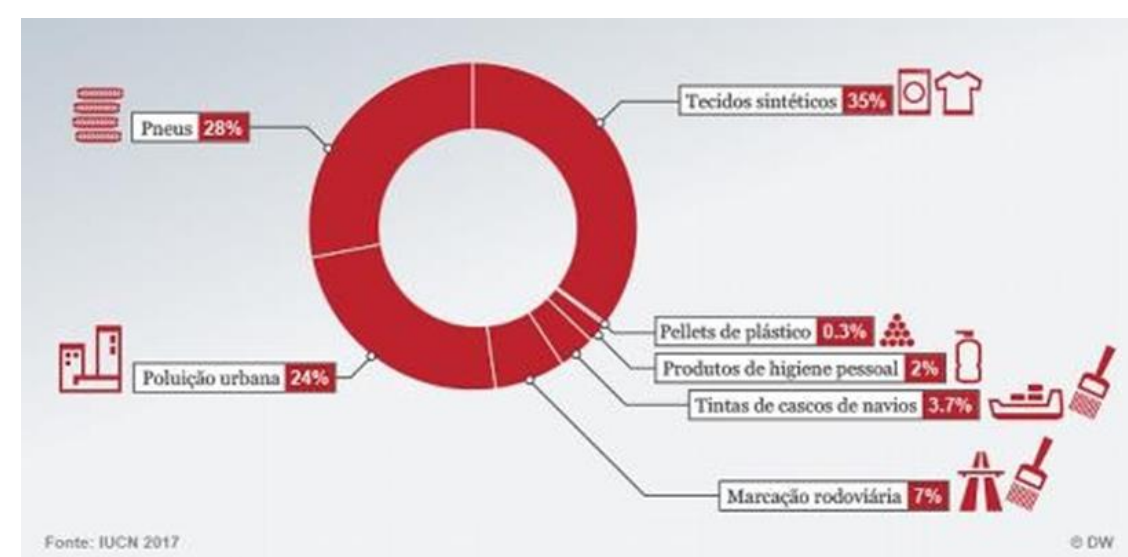

Fonte: SECRETÁRIA DA EDUCAÇÃO DE CURITIBA (2019) 
Os potenciais impactos associados aos microplásticos nos oceanos estão, em geral, ligados à sua ingestão por diversos animais marinhos, principalmente pelas espécies que compõem o zooplâncton, base da cadeia alimentar aquática (BROWNE et al., 2008; THOMPSON et al.,2004; VOPARIL et al., 2004; TEUTEN et al., 2007). Microplásticos foram encontrados em uma ampla variedade de comidas e bebidas como na água potável (KSUTH et al., 2017; MASON et al., 2018), em cervejas (LIEBEZEIT; LIEBEZEIT, 2014), no sal e no açúcar (RIST et al., 2018) e em comidas típicas de litorais (ROCHMAN et al., 2015). Os danos causados à saúde humana ainda estão em fase de pesquisa.

No entanto, não se trata de banir o uso destes tecidos, afinal ao seu uso podem estar associados benefícios sociais. "Para a Abipet (2016), o PET é o melhor e mais resistente plástico para fabricação de garrafas, frascos e embalagens para refrigerantes, águas, sucos, óleos comestíveis, medicamentos, cosméticos, produtos de higiene e limpeza, destilados, isotônicos, cervejas, entre vários outros" (LOPO, 2017, p. 4). Assim, seu uso, especialmente em relação ao PET reciclado, é renda para os catadores, reaproveita "centenas de milhares de toneladas de embalagens que seriam indevidamente destinadas", [e...] "economiza recursos naturais, muita água e energia" (LOPO, 2017, p. 4).

A questão é, portanto, pensar em formas de reduzir as emissões das microfibras plásticas. Lidar com essas ínfimas partículas é uma tarefa extremamente difícil, pois as estações de tratamento não conseguem filtrar as microfibras devido ao seu tamanho e removê-las do ambiente marinho é uma tarefa que representa um grande desafio tecnológico (JAMBECK et al., 2015). 
O objetivo, portanto, deve ser no sentido de reduzir as emissões de fiapos de microplástico e impedir que estes fiapos de microplástico cheguem aos oceanos, o que pode ser por meio de modificações no design têxtil, nas máquinas de lavar e/ou sistemas de filtragem urbanos (NAPPER; THOMPSON. 2016). Neste sentido, considerar o ciclo de vida de roupas, em especial daquelas de tecido sintético, é uma abordagem pertinente para propor intervenções em diferentes etapas de sua produção, visando diminuir a liberação das microfibras plásticas. De acordo com Vezzoli (2010) o ciclo de vida de um produto compreende as diferentes etapas de seu desenvolvimento, uso e fim de vida. Na análise do ciclo de vida (ACV), bem como na abordagem sistêmica (BISTAGNINO, 2009) ) considera-se os inputs e outputs (entradas e saídas) de matéria e energia relativas à cada etapa e, a partir destas informações é possível traçar um perfil do impacto ambiental de determinado produto ou sistema. Esta abordagem sistêmica possibilita identificar problemas bem como propor a introdução de melhorias visando uma produção mais próxima do conceito de sustentabilidade, não só no quesito ambiental, mas também em termos sociais e econômicos (omitido para revisão cega).

O esquema abaixo representa a cadeia de produção da indústria da moda incluindo a indústria têxtil e considerando alguns inputs e outputs relativos a cada etapa. Para o presente estudo interessa destacar a fase onde, de acordo com a revisão bibliográfica, se concentra a principal emissão de microfibras. Assim, destacou-se em amarelo a etapa de uso do produto, momento em que ocorre a lavagem das roupas; importante fonte de microfibras sintéticas para os oceanos. Outros pontos que merecem destaque são; a etapa de produção do tecido, que requer várias lavagens principalmente no tingimento, e o destino final da peça de 
roupa que na maioria das vezes pode acabar em lixões, se degradando a céu aberto com grande potencial de chegar às águas.

Figura 1: Cadeia de produção da moda

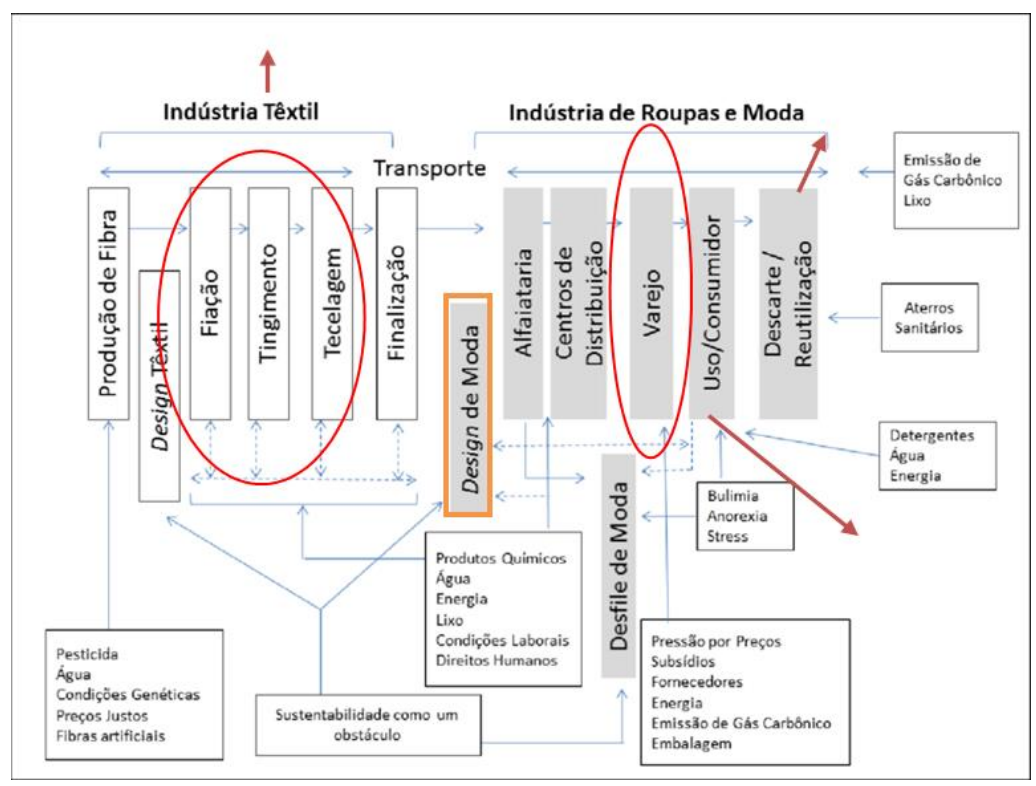

Fonte: FARIAS (2016) Adaptada pela autora

\section{Propostas de Intervenção}

Como destacado anteriormente, existem diferentes etapas em que é possível atuar no sentido de evitar a poluição das águas pelas microfibras. A partir da análise do ciclo de vida de uma peça de roupa selecionou-se duas propostas: uma localizada ainda na etapa de produção têxtil e outra na etapa de uso e, portanto, diretamente vinculada ao usuário da roupa. 


\title{
3.1 Tanden Repeat Coating
}

A tecnologia Tandem Repeat Coating foi desenvolvida a partir de proteínas específicas encontradas nos dentes dos anéis de espécies de lulas. Essas proteínas (SRT) possuem propriedades físico-químicas que, dentre oportunidades para a área médica e tecnológica, oferecem também soluções mais sustentáveis à indústria têxtil.

\begin{abstract}
A este respeito, as proteínas SRT são uma grande promessa de fornecer uma ampla gama de soluções para a indústria têxtil por causa de suas propriedades programáveis, biodegradabilidade e fácil processamento, como tecidos recicláveis, de autocura" (FRANCESCH; DEMIREL, 2019, p.8).
\end{abstract}

Especificamente no que se refere à emissão de microfibras têxteis, a tecnologia foi testada como um revestimento protetor e as "descobertas sugerem que os revestimentos SRT fornecem estabilidade mecânica às microfibras, podendo potencialmente prevenir a liberação de microfibras para o ambiente após a abrasão mecânica" (FRANCESCH; DEMIREL, 2019). 
Figura 2: Revestimentos de proteína SRT resistentes à abrasão para tecidos avançados. (a) Espectros FTIR de tecido de microfibra revestido com SRT e não revestido. (b) As microfibras não revestidas pré-abrasão são agrupadas, e (c) estão danificadas e desfiadas após o teste de abrasão. (d) As microfibras revestidas com SRT pré-abrasão também são agrupadas, mas (e) após o teste de abrasão as microfibras estão alinhadas e não danificadas.
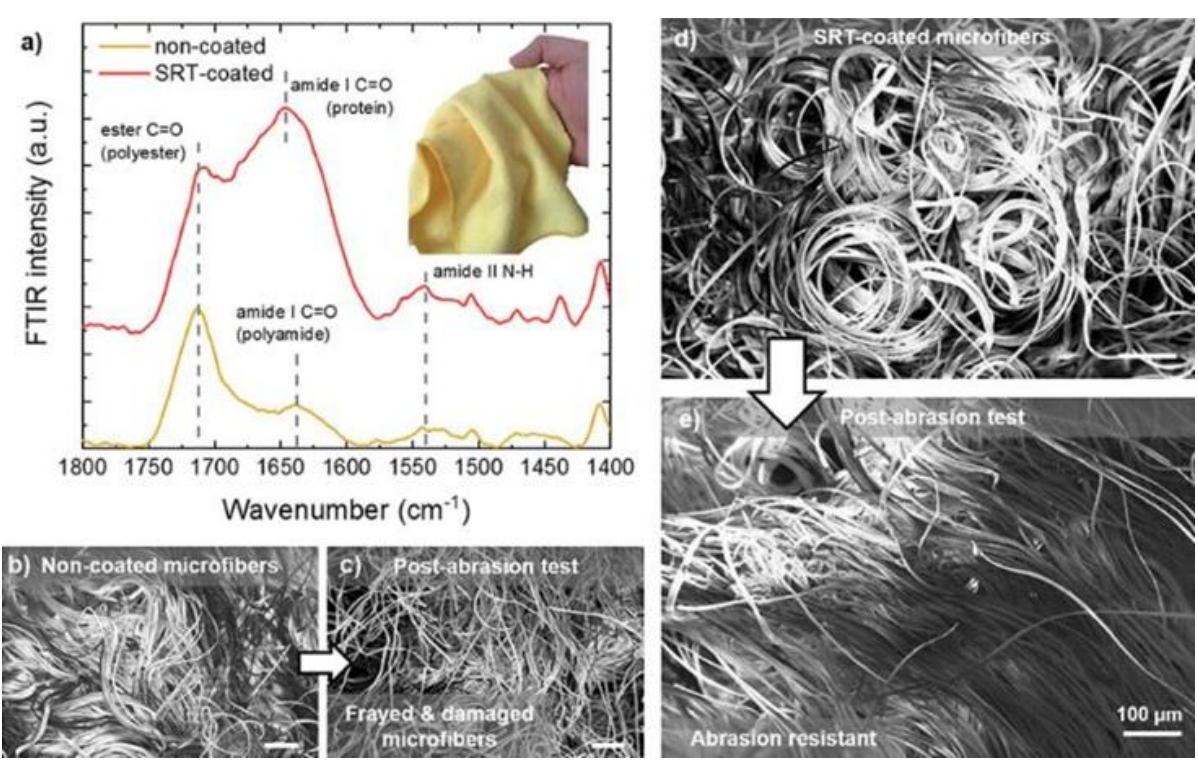

Fonte: FRANCESCH; DEMIREL (2019).

A aplicação do produto é simples, uma vez que pode ser "borrifado" com spray e sua presença não altera as características físicas do tecido (TANDEM REPEAT, 2018).

De acordo com Pena-Francesch e Demirel (2019) a obtenção das proteínas SRT pode se dar por extração, diretamente de ventosas de lula, ou por produção biossintética, a partir de sequenciamento do genoma. A autora demonstra que a obtenção biossintética de proteínas SRT é mais vantajosa que a extração direta da fonte natural dos tentáculos da lula que é limitada à disponibilidade e ao custo das fontes naturais. Primeiro por seu aspecto sustentável em relação à população das lulas (não esgota ou prejudica), segundo pela escalabilidade industrial e terceiro pela facilidade de controle e manipulação dos aminoácidos para inserção de novas características moleculares. 


\subsection{The Gupfriend Washing Bag}

O Guppyfriend é uma iniciativa da marca Langbrett em parceria com a STOP! MICROWASTE, uma organização alemã, sem fins lucrativos, com sede em Berlim, que se dedica a educar as pessoas em relação ao problema do plástico em lagos, rios e oceanos.

A proposta é simples e prática, consiste em um saco no qual as roupas de tecidos sintéticos são inseridas para então serem lavadas na máquina. Como na figura 4, após a lavagem as microfibras que se desprenderam dos tecidos ficam armazenadas no saco e devem ser retiradas para, então, serem descartadas no lixo.

Figura 4. Como utilizar o Guppyfriend
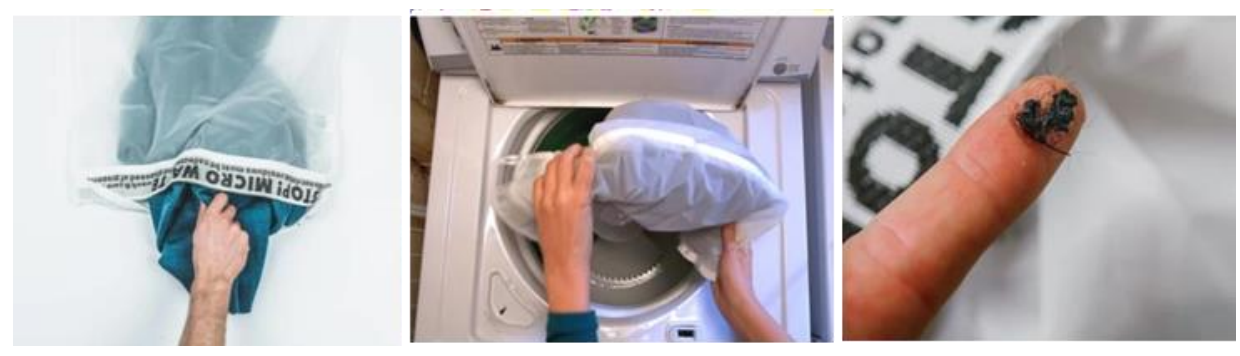

Fonte: GUPPYFRIEND (2018)

De acordo com o jornal inglês The Guardian (2017) o dispositivo não só captura as microfibras que se desprendem do tecido como também contribui para a redução de sua emissão ao diminuir o atrito entre as peças. A invenção foi testada por institutos científicos, universidades, representantes da indústria de moda e varejo e varejistas, durante um período de três anos. Os resultados demonstraram que o Guppyfriend tem a capacidade de reduzir a perda de microfibras pelos tecidos em até $86 \%$ e, retém quase $100 \%$ delas em seu interior. 
Para além da solução que é reconhecida pelos próprios criadores como 'apenas uma pequena contribuição' diante de um problema tão amplo e complexo, a proposta considera a necessidade de educar e conscientizar as pessoas.

Desenvolvemos soluções de filtros pragmáticos, como o Saco de Lavagem Guppyfriend, para educar os clientes sobre a poluição microplástica. Ao usar essas soluções práticas, as pessoas refletem sobre seus próprios rituais de compra e lavagem e começam a mudar seu comportamento.

Figura 5. a) The Guppyfriend; b) Ritual de lavagem com o Guppyfriend.
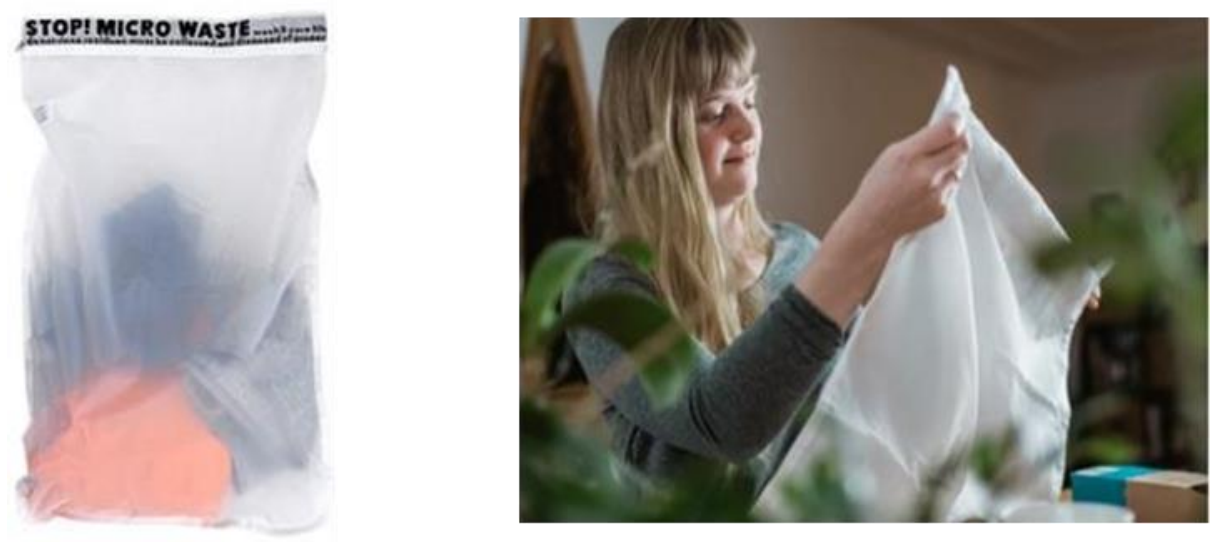

Fonte:a) SPEJDER SPORT (-) b) INSTAGRAM GUPPYFRIEND (2018)

Como pode ser visto a proposta se localiza na etapa de uso do ciclo de vida de uma peça de roupa estando, portanto, intimamente relacionada ao usuário que precisa ser sensibilizado para incorporá-la. Neste sentido percebe-se que o design está presente em todo o projeto do produto e de sua comunicação. A embalagem comunica a função do Guppyfriend através de um design gráfico simples e assertivo (Figura 6 ). O produto está presente nas redes sociais como Instagram e é vendido por marcas reconhecidas por sua abordagem sustentável para a moda como a Patagônia2 . A comunicação do produto está vinculada, portanto, a um estilo 
de vida saudável, de espírito jovem e preocupado com as questões ecológicas. Bem-estar e qualidade de vida são relacionados à proximidade e respeito à natureza.

Figura 6: Embalagem Guppyfriend;

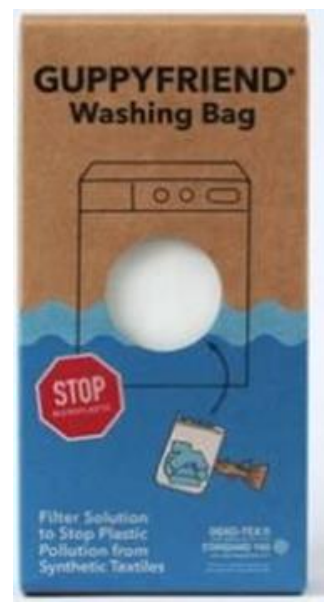

Fonte: GUPPYFRIEND (2021)

Figura 7: Estilo de vida natural da marca Langbrett

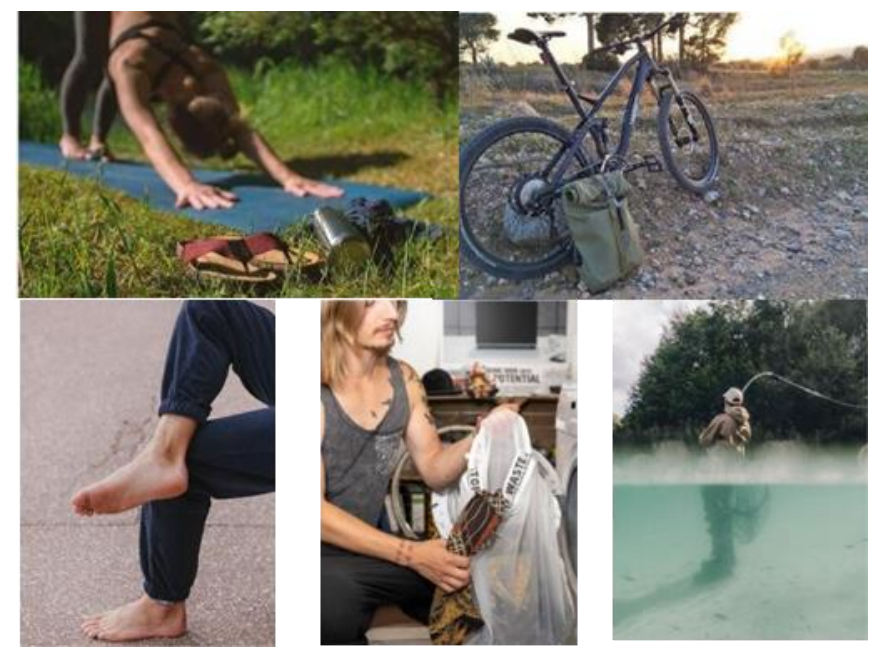

Fonte: INSTAGRAM LANGBRETT (2021) 
Figura 8: Estilo de vida natural da marca Patagônia.
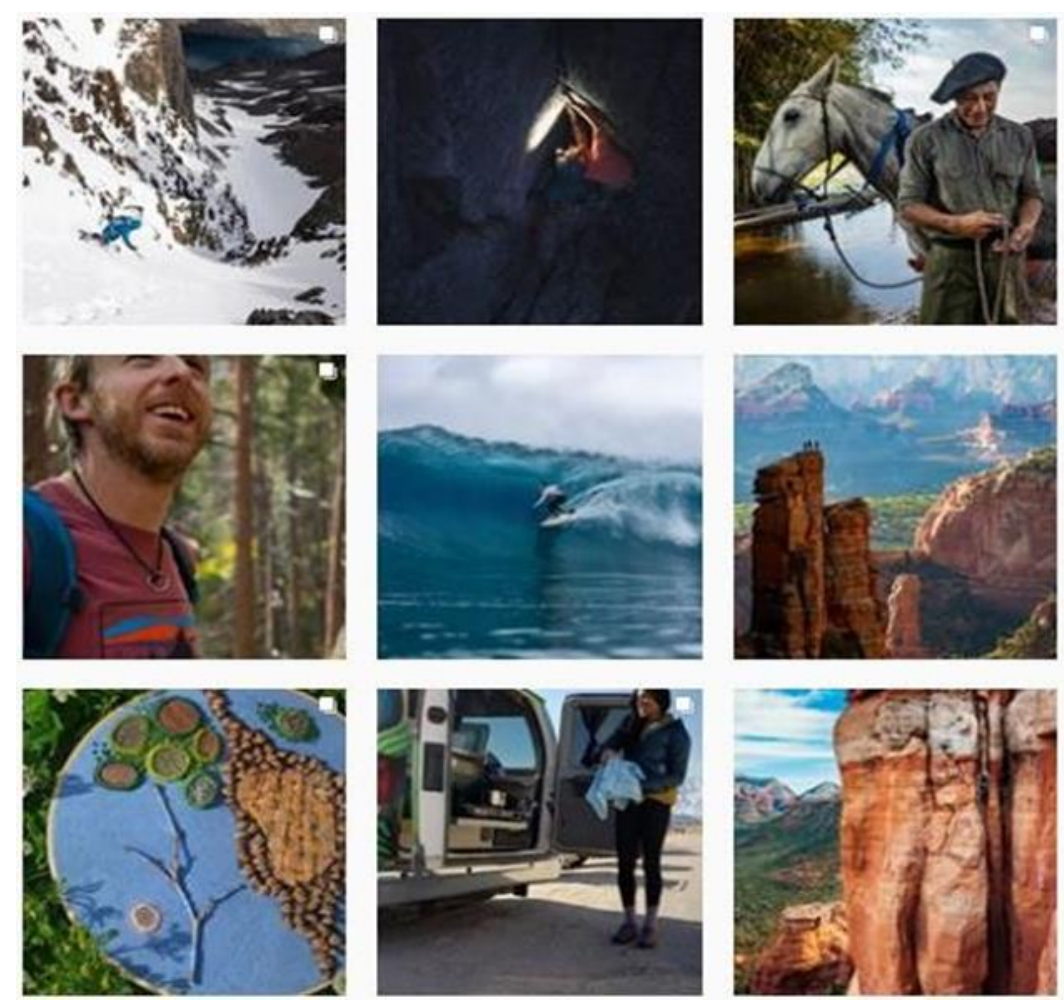

Fonte: INSTAGRAM PATAGÔNIA (2021)

\section{Discussão e conclusão}

A questão das microfibras se mostra complexa ao ser tratada no momento em que elas já se constituem em fator de poluição das águas. No entanto, a abordagem sistêmica, considerando todo ciclo de vida do produto, abre frestas com possibilidades de solução. As duas propostas apresentadas aqui variam em função da etapa de aplicação e da complexidade envolvida na solução. A tecnologia em torno do Tandem Repeat Coating envolveu pesquisas laboratoriais para testes com a proteína presente nos dentes dos anéis de lulas, o que a destaca como a solução mais complexa. Sua aplicação é feita durante a produção do tecido, demandando por parte da fábrica a inserção de mais uma etapa em suas operações, 
o que pode ser um percalço. Por outro lado, o fato de ser aplicada logo no início da cadeia do processamento têxtil aumenta sua eficiência, uma vez que protege o tecido, impedindo a liberação de microfibras em outros momentos do ciclo de vida anteriores à lavagem da roupa pelo consumidor. Cabe, por fim, algumas questões acerca de outros possíveis benefícios deste "revestimento": ao proteger o tecido evitando a quebra das fibras imagina-se que a qualidade visual têxtil estaria sendo, também, preservada. Este fato provavelmente contribui também para aumentar o tempo de vida da peça. Poderia ainda ser considerada a possibilidade do revestimento ser aplicado em tecidos naturais, de algodão por exemplo, conferindo a este, algumas características alcançadas em sua união com o poliéster. Estas e outras hipóteses, atraentes pela sua abordagem sustentável, parecem promissoras suscitando novas pesquisas sobre essa tecnologia na área da moda.

O Guppyfriend é uma solução simples (de fácil produção e acesso) e eficaz pois retém quase $100 \%$ das microfibras. Um ponto interessante e que merece atenção é o envolvimento do consumidor para o sucesso da proposta. Se por um lado promove a sensibilização quanto ao impacto gerado pelo simples ato de lavar uma roupa, por outro, demanda maiores esforços para alcançar e convencer uma grande quantidade de pessoas, o que é fundamental para a efetividade da proposta. Um problema, aparentemente ainda não resolvido, é o descarte das fibras que devem ser removidas do interior do Guppy Friend. Evita-se que saiam direto das máquinas para os ambientes aquáticos, porém, se não forem corretamente descartadas, como garantir que não acabarão no mesmo lugar?

A partir deste estudo percebe-se que a questão dos microplásticos não possui apenas uma solução, demanda 
esforços múltiplos que considerem os diferentes momentos do ciclo de vida de uma peça confeccionada por tecidos sintéticos.

Com os casos aqui tratados, ressalta-se o potencial de ideias simples, a efetividade/ praticidade de conhecimentos complexos e, principalmente, o quanto estas iniciativas se complementam. Esse fato exemplifica o valor do princípio dos relacionamentos da abordagem do Design Sistêmico, que defende:

uma visão global de todos os elementos, atividades e estratégias envolvidas, que resulta em um tratamento como um todo único, buscando a prosperidade, não apenas de um negócio, mas de toda rede. Ao invés da divisão em partes e tratamento isolado, que muitas vezes chega apenas a soluções parciais ou mesmo cria instabilidade em outros elementos, a Rede Sistêmica trabalha a eficiência do todo, aceitando o desafio da busca de equilíbrio dos sistemas complexos (omitido para revisão cega).

\section{REFERÊNCIAS}

ANDRADY, A. L., 2011. Microplastics in the marine environment. Marine Pollution Bulletin, pp. 1596-1605.

BARNES, David K. A et al. (2009) 'Accumulation and fragmentation of plastic debris in global environments.' Philosophical Transactions of the Royal Society B, 364, 1985-1998. http://rstb.royalsocietypublishing.org/. Accessed 20 october 2018.

BISTAGnino, L. Design sistemico. Progettare la sostenibilità produttiva e ambientale. [s.l.] Slow Food, 2009.

CARVALHAL, André (2016), Moda com propósito, São Paulo:Schwarcz s.a.

(omitido para revisão cega) 
FARIAS, Mariana. Consumo consciente de moda e o metabolismo futuro do guarda-roupa: uma abordagem quantitativa com mulheres residentes do interior de são paulo (sp). 2016. 241 f. Dissertação (Mestrado profissional em Administração - Faculdade de Gestão e Negócios, Universidade Metodista de Piracicaba, Piracicaba, 2016.

FLETCHER, Kate and GROSE, Lynda (2011), Moda \& sustentabilidade. Design para a mudança, São Paulo: Senac São Paulo.

PENA-FRANCESCH A and DEMIREL MC (2019). SquidInspired

Tandem Repeat Proteins: Functional Fibers and Films. Front. Chem. 7:69

GADDES, D. et al., 2016. Self-Healing Textile: Enzyme Encapsulated Layer-by-Layer Structural Proteins. ACS Appl. Mater. Interfaces., 15 July, p. 20371-20378.

GUPPYFRIEND. Bolsa de lavagem Guppyfriend.

Disponível em:

https://guppyfriend.com/products/guppyfriend-

waschbeutel- kaufen. Acesso em: setembro 2019

GUPPYFRIEND. @guppyfriend. Disponível em:

https://www.instagram.com/guppyfriend/. Acesso em: setembro2020.

GWILT, Alison (2014), Moda sustentável. Um guia prático, São Paulo: Gustavo Gili.

HENRY, B; LAITALA, K and KLEPP, I.G. (2018) ' Microfibres from apparel and home textiles: Prospects for including microplastics in environmental sustainability assessment.' Science of the Total Enviroment, 652, 483494.

www.Elsevier.com/locate/scitotenv. Accessed 20 october 2018.

JAME MOORE, C., 2015. How Much plastic is in the ocean? Youtell me!. Long Beach: Elsevier.

JAMBECK, J; et all.(2015) 'Plastic waste inputs from land into the ocean.' Marine Pollution. Sciencemag,347: 6223, 768-771. https://www.sciencemag.org/. Accessed 20 october 2018.

KOSUTH, M., WATTENBERG, E.V., MASON, S.A., TYREE, C.,

Morrison, D., 2017. Synthetic Polymer Contaminating Global Drinking Water. Disponível em: https://orbmedia.org/stories/invisibles_final_report. Acesso em 30 outubro 2018. Acesso em: 30 outubro 2018.

LANGBRETT. @langbrett. Disponível em: https://www.instagram.com/langbrett/. Acesso em: setembro 2020. 
LIEBEZEIT, G., LIEBEZEIT, E., 2014. Synthetic particles as contaminants in German beers. Food Addit. Contam., Part A 31 (9), 1574-1578. https://www.ncbi.nlm.nih.gov/pubmed/25056358.

Accessed 30 october 2018.

LOPO, W. N. Uso do PET Reciclado em Tecidos de Malha: Estudo Bibliográfico e Exploratório. REAI - Revista de Estudos Acadêmicos Interdisciplinar - UNIFEB, v. 1, n. 1, 2017.

(omitido para revisão cega)

NAPPER, I. E. \& THOMPSON, R. C. (2016) 'Release of synthetic microplastic plastic fibres from domestic washing machines: Effects of fabric type and washing conditions.' Marine Pollution Bulletin, 112, 39-45. www.Elsevier.com/locate/masporbul.

Accessed 20 october 2018.

PATAGONIA. @patagonia. Disponível em: https://www.instagram.com/patagonia/. Acesso em setembro 2020.

ROCHMAN, C.M, TAHIR, A., WILLIAMS, S.L., BAXA, D.V., LAM, R.,

MILLER, J.T., The, F.C., WERORILANGI, S., The, S.J., 2015.

Anthropogenic debris in seafood: plastic debris and fibers from textiles in fish and bivalves sold for human consumption. Scientific Reports volume 5, Article number: 14340. https://www.nature.com/articles/srep14340. Accessed 30 october 2018.

RIST, S., ALMROTH, B.C., HARTMANN, N.B., KARISSON, T.M., 2018.

A critical perspective on early communications concerning human health aspects of microplastics. Sci. Total Environment. 626. 720-726. https://www.ncbi.nlm.nih.gov/pubmed/29396337.

Accessed 30 october 2018.

SECRETARIA DA EDUCAÇÃO DE CURITIBA. Luta contra OS

microplásticos.Disponível em:

http://www.biologia.seed.pr.gov.br/modules/noticias/article .php?s toryid=1259\&tit=Luta-contra-os-microplasticos. Acesso em:setembro 2020.

SPEJDER SPORT. Guppy Friend Zero MicroWaste vaskepose. Disponível em: https://www.spejdersport.dk/guppy-friend-zeromicrowaste. Acesso em: setembro 2020.

TEXTILE WORLD. Man-Made Fibers Continue To Grow. Disponível em: https://www.textileworld.com/textile- 
world/fiber- world/2015/02/man-made-fibers-continue-togrow/. Acesso em 25de setembro de 2018.

THE GUARDIAN. Microfibers are polluting our food chain. Thislaundry bag can stop that.

Disponível em:

https://www.theguardian.com/sustainable-

business/2017/feb/12/seafood-microfiber-pollution-

patagonia- guppy-friend. Acesso em 18 de novembro de 2018.

VEZZOLI, Carlo (2010), Design de sistema para sustentabilidade: teoria, métodos e ferramentas para o design sustentável de "sistema de satisfação", Salvador: EDUFBA 